\title{
Impact of Physical Education and Sports in Promoting Social Values among Youth
}

\author{
Ravi $\operatorname{Kumar}^{1} *$
}

\section{ABSTRACT}

The purpose of this study is to investigate the impact of physical education and sports in promoting social values among youth. Physical education and sports plays a vital role in educating the youth regarding the importance of social values in their life. Reviewed literature investigated that the importance of association in educating both minds and body. Further, it also encourages the social values among youth that allow them to develop the social relations with their community. Moreover, the benefits of physical education and sports can influence both academic learning and physical activity of the youth.

Keywords: Physical Education, Sports, Social Values, Youth, Academic Learning.

In present era, physical education and sports is an essential part of education. It contributes directly to development of physical competence and fitness. It also helps the youth to be aware of the worth of leading a physically active lifestyle. The healthy and physically active youth is more likely to be academically motivated, attentive, and promising. In other words, we can say that physical education and sports is exclusive to the school core curriculum. It is the only programme that provides the opportunities to youth to learn motor skills, progress mental and physical fitness. The benefits of physical gained from physical activity such as disease prevention, safety and injury avoidance, decreased morbidity and premature mortality, and increased mental health. The physical education is only the course where youth learn about all of the benefits gained from being physically active as well as the skills and knowledge to incorporate safe, satisfying physical activity into their lives, in addition, how to interact with others (National Association for Sport and Physical Education, 2001). Moreover, it is observed that physical education sessions should be easy to get from preschool until secondary. It target to deal with a variety of physical activities and encourage those who are lack of leaning to take up planned competitive sports. This involves discard conventional methods of physical education teaching and focusing more on the individuals' needs and abilities, as an alternative of the

\footnotetext{
${ }^{1}$ Lecturer in Physical Education GHSS, Katra, Vaishno Devi, J\&K, India

*Responding Author

Received: January 13, 2017; Revision Received: February 3, 2017; Accepted: February 7, 2017

(C) 2017 Kumar R; licensee IJIP. This is an Open Access Research distributed under the terms of the Creative Commons Attribution License (www.creativecommons.org/licenses/by/2.0), which permits unrestricted use, distribution, and reproduction in any Medium, provided the original work is properly cited.
} 
enjoyment of physical activity. As time for physical education is generally limited within the school time schedule and curriculum, its content must be valuable and resourceful (Fox and Harris, 2003). Further Gonzalez et al. (2010) believed that curricular physical education within any sport, not only talent development scheme but a high development in social values among youth. Therefore, the purpose of this study is to investigate the role of physical education in promoting social values among youth.

\section{Physical Education Programme}

Physical education curriculum can offer youth with the appropriate knowledge, skills, behaviours, and confidence to be physically active for life. Moreover, physical education is the basis of a school's physical activity programme. In the same vein, participation in physical activity is correlated with academic advantages like improved concentration, memory, and classroom behaviour. According to World Health Organization (2001), it includes development of physical abilities and physical conditioning; motivating the students to continue sports and physical activity; and providing recreation activities.

\section{Development of Physical Abilities and Physical Conditioning}

Physical education facilitates to build up and practise physical fitness entails basic motor skills (Barton et al. 1999) and gets hold of the competency to perform various physical activities and exercises. Physical fitness builds mentally sharper, physically comfortable and also able to deal with the day-to-day demands (Jackson, 1985). Further, endurance, flexibility, strength and coordination are the key components of physical fitness. Moreover, to execute the physical exercises and sport, youth must be developed basic motor skills.

\section{Motivating the Students to Continue Sports and Physical Activity}

Teachers always motivate the youth to contribute in sports and physical activities as well as academic education programmes. Further, they always direct and instruct them, sports and physical activity are vital part of academic education. They have also guided the youth; we cannot think wholesome development of human personality without sports and physical education. Moreover, they have also to manage a meeting in which discusses their parents about the importance of sports and physical activity as well as academic education. Further, teachers must engage parent or family members in physical activity, for example, by giving youth physical activity 'homework' which could be performed together with the parent's viz., family walks after supper or playing in the park (WHO, 2001).

\section{Providing recreation activities}

Institutions must focuses on implementation of physical activity course which facilitate to make enjoyable participation to all youth in physical activity programme which provides the youth with a collection of ideas for active games and activities and the skills and fitness to play them (Fox and Harris, 2003) in order to reduce the stress, anxiety, drug abuses and obesity. 
Impact of Physical Education and Sports in Promoting Social Values among Youth

\section{Promoting the Social Values among Youth}

Physical education and sports play a vital role in promoting the social values among the youth. Moreover, physical education is considered as a school subject, which facilitate to prepare the youth for a healthy lifestyle and focuses on their overall physical and mental development, as well as imparting important social values among the youth such as fairness, self-discipline, solidarity, team spirit, tolerance and fair play (Bailey, 2005).

\section{DISCUSSION AND CONCLUSION}

The present study focuses on physical education and sports helps to promote the social values among youth. Physical education and sports are considered as an essential part of education and culture. It build up the abilities, will-power, moral values and self-discipline of every human being as an entirely integrated member of society. The contribution of physical activity and the practice of sports must be certify that the throughout life by means of a global, lifelong and democratized education. It contributes to the preservation and enhancement of mental and physical health, gives a nourishing leisure-time activity and also helps to an individual to overcome the drawbacks of present stressful living. At the community level, they build up social qualities, social relations and also fair play, which is vital not only to sport itself but also to life in society. Education system must allocate the required position and applicable to physical education and sport in order to create a balance and strengthen between physical activities and other components of education. Physical education and sport course must be intended to suit the requisites and personal attributes of those follow them, as well as the institutional, cultural, socio-economic and climatic conditions of each country. In the process of education in general, physical education and sport programmes must, by virtue of their content and their timetables, help to create habits and behaviour patterns beneficial to full development of the human personality. Further, voluntary people, given appropriate training and supervision, can make an invaluable contribution to the inclusive expansion of sport and promote the participation of the inhabitants in the training and association of physical and sport activities. In addition, it also focuses on adequate and sufficient facilities and equipment which meet the needs of exhaustive and safe participation in both in-school and out-of-school programmes regarding physical education and sport. Physical education as a generic term is linked with socio-cultural, educational and social values, psycho-social qualities, socialization, inclusion, moral codes of behaviour, cognitive and physical development, well-being, healthy diet and other benefits to be derived from engagement in regular physical activity (Bailey, 2005). To conclude, education in general, and physical education in particular, should respond to the needs of optimally developing individuals' capabilities and provide opportunities for personal fulfillment and social interactions, fundamental in human co-existence.

\section{Limitations and Future Research}

The major limitations of this study are that lack of participation of students in physical activities. In future research, school management should organize the seminar and workshop in which 
aware the students about the importance of physical activity programmes. Further school management should also make compulsory the physical activity programmes. In future research should also include broader aspects of physical activity and assess the multidimensional nature of self-esteem. Further, this study is conceptual in nature; empirical study should be done in order to improve the generalisability of the findings.

\section{Acknowledgments}

The author appreciates all those who participated in the study and helped to facilitate the research process.

Conflict of Interests: The author declared no conflict of interests.

\section{REFERENCES}

Bailey, R. (2005). Evaluating the relationship between physical education, sport and social inclusion. Education Review, 57 (1), 71-90.

Barton, G.V., Fordyce, K., \& Kirby, K. (1999). The importance of the development of motor skills to children. Teaching Elementary Physical Education, 10 (4), 9-11.

Fox, K.R., \& Harris, J. (2003). Promoting physical activity through schools. In: McKenna J, Riddoch C, eds. Perspectives on health and exercise. Basingstoke, New York: PalgraveMacmillan.

Gonzalez, M.C., Regalado, M.N.M., Guerrero, J.T. (2010). Teaching and learning social values: Experience of resolution of conflicts in the classroom of physical education across the learning of social skills. Journal of Human Sport and Exercise, 5 (3), 497-506.

Jackson, G. (1985). A family guide to fitness and exercise. London: Salamnder Books Limited.

The National Association for Sport and Physical Education (NASPE, 2001). An association of the American alliance for health, physical education, recreation and dance.

World Health Organization. (2001). Evaluation in health promotion: Principles and Perspective. WHO Regional Office for Europe.

How to cite this article: Kumar R (2017), Impact of Physical Education and Sports in Promoting Social Values among Youth, International Journal of Indian Psychology, Volume 4, Issue 2, No. 88, ISSN:2348-5396 (e), ISSN:2349-3429 (p), DIP:18.01.069/20170402, ISBN:9781-365-74161-6 